\title{
Low antioxidant status of patients with central nervous system infections
}

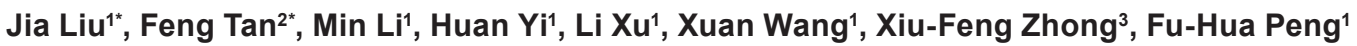 \\ 'Department of Neurology, the Third Affiliated Hospital of Sun Yat-sen University, Guangzhou 510630, Guangdong, China. \\ ${ }^{2}$ Department of Neurology, Foshan Hospital of Traditional Chinese Medicine, Guangzhou University of Chinese Medicine, Foshan 528000, Guangdong, China. \\ ${ }^{3}$ Ophthalmology State Key Laboratory of Ophthalmology, Zhongshan Ophthalmic Center, Sun Yat-sen University, Guangzhou 510060, Guangdong, China. \\ *The first two authors contributed equally to this paper.
}

Correspondence to: Dr. Fu-Hua Peng, Department of Neurology, the Third Affiliated Hospital of Sun Yat-Sen University, Tian He Road No. 600, Guangzhou 510630, Guangdong, China. E-mail: pfh93@163.com

How to cite this article: Liu J, Tan F, Li M, Yi H, Xu L, Wang X, Zhong XF, Peng FH. Low antioxidant status of patients with central nervous system infections. Neuroimmunol Neuroinflammation 2016;3:262-7.

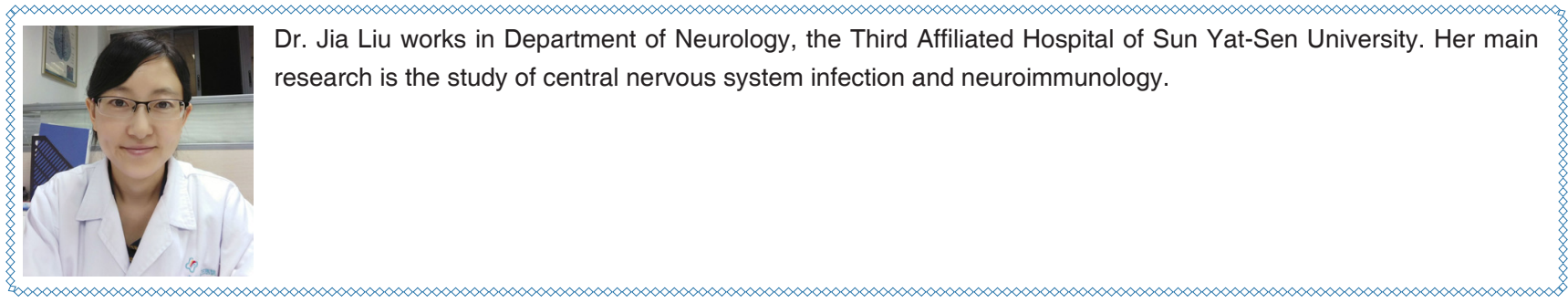

\section{Article history:}

Received: 22-04-2016

Accepted: 01-09-2016

Published: 15-12-2016

\section{Key words:}

Antioxidant,

uric acid,

bilirubin,

albumin,

central nervous system infection

\section{ABSTRACT}

Aim: The pathogenesis of central nervous system infections (CNSI) has not been fully understood; some studies indicated that reactive oxygen species may induce brain damage. The aim of our study was to investigate serum antioxidant status in patients with CNSI. Methods: The serum levels of uric acid (UA), bilirubin and albumin of 548 individuals were enrolled in our study, comprising of 114 healthy controls (HC) and 434 patients with five different kinds of CNSI, which including viral meningitis and/or meningoencephalitis, cysticercosis of brain, tuberculous meningitis and/or meningoencephalitis, cryptococcus meningitis and/or meningoencephalitis, and bacterial meningitis and/or meningoencephalitis. Results: The data suggested that there were reducing levels of oxidation state (serum UA, bilirubin and albumin) in CNSI patients when compared with HC. Likewise, similar results were observed when cohorts were divided into male and female subgroups. Conclusion: The authors demonstrated that serum antioxidant status in patients with CNSI was lower; the reason may be due to exhaustion of antioxidant capacity. Therefore, enhancing antioxidant power and keeping oxidative stress and antioxidants in balance may be beneficial to the patients with CNSI. 


\section{INTRODUCTION}

The pathogenesis of central nervous system infections (CNSI) has not yet been completely understood, but some scholars have indicated that oxidative stress and antioxidant imbalance may induce brain injury. Reactive oxygen species (ROS) and reactive nitrogen species (RNS) may play a vital role in certain pathological processes acting as inflammatory agents causing intracranial complications. ${ }^{[1,2]}$ ROS, such as superoxide anion, hydrogen peroxide or hydroxyl radicals, may result in damage to cellular DNA, proteins and lipids, and even causing cell death. ${ }^{[3]}$ RNS, such as peroxynitrite (ONOO-), is a strong oxidant that can be cytotoxic including nitrotyrosine or lipidperoxidation in bacterial meningitis. ${ }^{[4]}$ Oxidative stress, which plays a major role in disease pathogenesis, is defined as an imbalance in ROS and antioxidants. Cells use enzymatic and non-enzymatic antioxidants to control ROS levels to maintain an appropriate cellular redox balance. If antioxidant capacity is exhausted, an imbalance between oxidant and antioxidant status will lead to a state of oxidative stress, which could change the susceptibility of membranes and inactive biological molecules to damage..$^{[5-7]}$ Therefore, enhanced antioxidant protection and restored native homeostasis may be beneficial to the treatment of CNSI.

Uric acid (UA), as a scavenger of peroxynitrite, could inhibit central nervous system (CNS) inflammation and change blood-CNS barrier permeability, is considered to have a neuroprotective role..$^{[8-10]}$ Endogenous bilirubin converted from biliverdin, is an end product of heme degradation by biliverdinreductase (BVR). ${ }^{[1]}$ Some studies confirmed that bilirubin could effectively block seizure-induced ROS and play a role in cerebroprotective effects. ${ }^{[12]}$ Albumin, accounting for about $70 \%$ of the plasma colloid osmotic pressure, plays a vital role in maintaining the normal fluid distribution and constitutes the main circulating antioxidant system in the body. As potent scavengers of ROS derived from oxidative stress, albumin is the major source of extracellular reduced sulfhydryl groups $(-\mathrm{SH}){ }^{[13]}$

That is to say, UA, total bilirubin (Tbil) and albumin, are the major nonenzymatic antioxidant components of serum. ${ }^{[14]}$ However, the situation of antioxidant status in different patterns of CNSI has not fully been investigated. Therefore, we retrospectively evaluated the antioxidant status of serum UA, bilirubin and albumin in patients with CNSI.

\section{METHODS}

We retrospectively reviewed the clinical data of 598 patients with CNSI who were hospitalized in the Third Affiliated Hospital of Sun Yat-sen University from January 2008 to June 2015. A total of 434 CNSI patients satisfying the diagnostic criteria were recruited in our study. Another 114 healthy subjects came to our hospital for check-ups at the same period and served as control patients. CNSI patients were divided into 5 groups: viral meningitis and/or meningoencephalitis (VM), cryptococcus meningitis and/or meningo-encephalitis (CM), tuberculous meningitis and/or meningoencephalitis (TM), bacterial meningitis and/or meningoencephalitis (BM), cysticercosis of brain (BC) [Figure 1]. For the diagnosis of meningitis and Neurocysticercosis, we took into account the patient history, symptomatology, along with regional epidemiology, and basic cerebrospinal fluid testing. ${ }^{[15,16]}$

Demographic and clinical features of patients with CNSI and healthy controls (HC) are shown in Tables 1 and 2 .

Venous blood samples were drawn in the morning after patients' admission. Total serum UA, albumin and bilirubin concentrations were measured using a Clinical Analyzer 7180-ISE (Hitachi High-Technologies, Tokyo, Japan). Serum UA concentrations were measured using a UA assay kit based on the direct enzymatic oxidation of uric acid. Serum bilirubin concentrations were also measured by an enzymatic method with bilirubin oxidase.

The following subjects were excluded (1) patients

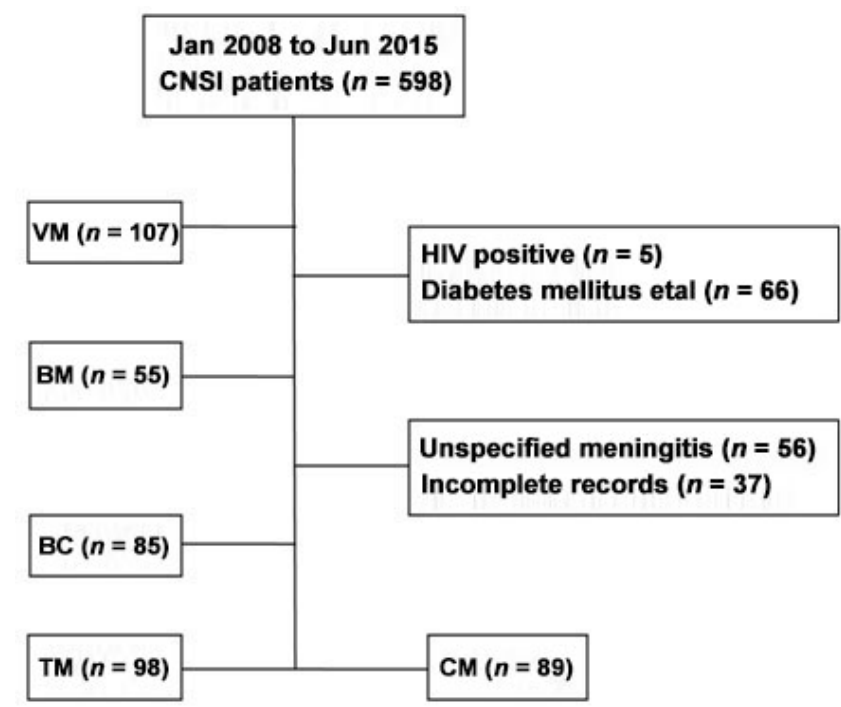

Figure 1: Enrollment process of patients. CNSI: central nervous system infections; VM: viral meningitis and/or meningoencephalitis; BC: cysticercosis of brain; TM: tuberculous meningitis and/or meningoencephalitis; $\mathrm{CM}$ : cryptococcus meningitis and/or meningoencephalitis; BM: bacterial meningitis and/or meningoencephalitis; HIV: human immunodeficiency virus 
Table 1: Demographic of patients with CNSI and healthy control

\begin{tabular}{|c|c|c|c|c|c|}
\hline Patients & No. of patients & Male & Female & Ages (mean \pm SD) & $\boldsymbol{P}$ \\
\hline Healthy control & 114 & 71 & 43 & $37.76 \pm 10.21$ & \\
\hline Viral meningitis and/or meningoencephalitis & 107 & 60 & 47 & $35.15 \pm 13.38$ & 0.061 \\
\hline Cysticercosis of brain & 85 & 50 & 35 & $35.67 \pm 12.75$ & 0.231 \\
\hline $\begin{array}{l}\text { Tuberculous meningitis and/or } \\
\text { meningoencephalitis }\end{array}$ & 98 & 56 & 42 & $35.98 \pm 15.58$ & 0.369 \\
\hline $\begin{array}{l}\text { Cryptococcus meningitis and/or } \\
\text { meningoencephalitis }\end{array}$ & 89 & 62 & 27 & $37.81 \pm 12.88$ & 0.437 \\
\hline $\begin{array}{l}\text { Bacterial meningitis and/or } \\
\text { meningoencephalitis }\end{array}$ & 55 & 40 & 15 & $35.64 \pm 19.43$ & 0.377 \\
\hline
\end{tabular}

CNSI: central nervous system infections; P: ages of patients with CNSI vs. ages of healthy control

Table 2: Presenting clinical symptoms of CNSI (\%)

\begin{tabular}{lccccc}
\hline Characteristics & $\begin{array}{c}\text { Viral meningitis } \\
\text { and/or }\end{array}$ & $\begin{array}{c}\text { Cysticercosis } \\
\text { of brain }\end{array}$ & $\begin{array}{c}\text { Tuberculous } \\
\text { meningitis and/or } \\
\text { meningoencephalitis }\end{array}$ & $\begin{array}{c}\text { Cryptococcus } \\
\text { meningitis and/or } \\
\text { meningoencephalitis }\end{array}$ & $\begin{array}{c}\text { Bacterial } \\
\text { meningitis and/or } \\
\text { meningoencephalitis }\end{array}$ \\
\hline Number & 107 & 85 & 98 & 89 & 55 \\
Headache & $105(98.1 \%)$ & $46(54.1 \%)$ & $98(100 \%)$ & $89(100 \%)$ & $55(100 \%)$ \\
Fever & $103(96.3 \%)$ & 0 & $96(97.9 \%)$ & $79(88.8 \%)$ & $54(98.2 \%)$ \\
Vomit & $69(64.5 \%)$ & $12(14.1 \%)$ & $57(58.2 \%)$ & $71(79.8 \%)$ & $42(76.4 \%)$ \\
Seizure & $4(3.7 \%)$ & $53(62.4 \%)$ & $9(9.18 \%)$ & $6(6.74 \%)$ & $1(1.82 \%)$ \\
\hline
\end{tabular}

CNSI: central nervous system infections

Table 3: Serum UA, bilirubin and albumin levels in patients with CNSI and HC (mean \pm SD)

\begin{tabular}{|c|c|c|c|c|c|c|}
\hline Patients & Total & Male & Female & $P^{1 \dagger}$ & $P^{2 \dagger}$ & $P^{3 \dagger}$ \\
\hline $\mathrm{UA}(\mu \mathrm{mol} / \mathrm{L})$ & & & & & & \\
\hline CNSI & $253.91 \pm 135.90$ & $278.59 \pm 146.33$ & $214.97 \pm 107.18$ & & & \\
\hline$\underset{\text { Tbil (umol/L) }}{\mathrm{HC}}$ & $336.31 \pm 109.36$ & $389.00 \pm 99.95$ & $252.13 \pm 88.43$ & $<0.001$ & $<0.001$ & 0.018 \\
\hline CNSI & $13.67 \pm 9.20$ & $14.89 \pm 10.41$ & $11.69 \pm 6.19$ & & & \\
\hline $\mathrm{HC}$ & $15.88 \pm 6.03$ & $16.92 \pm 5.95$ & $15.47 \pm 5.97$ & 0.015 & 0.099 & 0.001 \\
\hline $\begin{array}{l}\text { Ibil }(\mu \mathrm{mol} / \mathrm{L}) \\
\mathrm{CNSI}\end{array}$ & & & & & & \\
\hline $\begin{array}{l}\text { CNSI } \\
\mathrm{HC}\end{array}$ & $\begin{array}{l}10.18 \pm 6.43 \\
1283+4.51\end{array}$ & $\begin{array}{l}10.98 \pm 7.23 \\
13.48+5.04\end{array}$ & $\begin{array}{c}8.87 \pm 4.51 \\
1266+4.46\end{array}$ & $<0 \cap 01$ & 0005 & $<0001$ \\
\hline Albumin ( $g / L)$ & & & & & & \\
\hline $\begin{array}{l}\text { CNSI } \\
\mathrm{HC}\end{array}$ & $\begin{array}{l}41.80 \pm 5.16 \\
47.10 \pm 2.83\end{array}$ & $\begin{array}{l}42.15 \pm 5.33 \\
47.64 \pm 2.93\end{array}$ & $\begin{array}{l}41.26 \pm 4.83 \\
46.95 \pm 2.39\end{array}$ & $<0.001$ & $<0.001$ & $<0.001$ \\
\hline
\end{tabular}

$P^{1 \dagger}$ : CNSI vs. HC; $P^{2 \dagger}$ : male patients with CNSI vs. male HC; $P^{3 t}$ : female patients with CNSI vs. female HC; UA: uric acid; CNSI: central nervous system infections; HC: healthy control; Tbil: total bilirubin; Ibil: indirect bilirubin

with diabetes mellitus, renal failure, malignancies, abnormal liver function or human immunodeficiency virus infection; (2) patients who were taking diuretics, aspirin or other drugs that could affect serum UA levels; and (3) individuals who refused to participate in the study.

\section{Statistical analysis}

Data were analyzed using SPSS statistical software (version 17.0, Chicago, IL, USA). Numerical variables were presented as mean \pm standard deviation (SD), and categorical variables were expressed as percentage. A $P$ value $<0.05$ was considered significant. In order to reduce the effect of age, the differences between serum UA, bilirubin and albumin levels were analyzed using covariance analysis with age as covariant. Moreover, patients within each group were divided into male and female subgroups to eliminate the gender effect. Least significant difference $t$-test was used to test distinction between each two groups.

\section{RESULTS}

The analysis data for serum UA, bilirubin and albumin levels in patients with $\mathrm{CNSI}$ and $\mathrm{HC}$ are shown in Table 3. We observed that total serum UA levels of CNSI patients $(253.91 \pm 135.90 \mu \mathrm{mol} / \mathrm{L})$ were significantly lower when compared with HC group (336.31 $\pm 109.36 \mu \mathrm{mol} / \mathrm{L}, P<0.001)$. In each group of CNSI, serum UA levels were significantly lower than $\mathrm{HC}$ independent of the classification [Table 4]. Besides, in order to reduce the effect of gender, we divided each group into male and female subgroups. In male subgroups, serum total UA levels of CNSI $(278.59 \pm 146.33 \mu \mathrm{mol} / \mathrm{L})$ were significantly lower than male HC $(389.00 \pm 99.95 \mu \mathrm{mol} / \mathrm{L}, P<0.001)$ [Table 3]. In addition, in each male CNSI group, serum UA levels were also lower than those of male $\mathrm{HC}(P<0.05)$ [Table 4]. In female groups, we found that levels of serum UA in female CNSI $(214.97 \pm 107.18 \mu \mathrm{mol} / \mathrm{L})$ were also lower than female $\mathrm{HC}(252.13 \pm 88.43 \mu \mathrm{mol} / \mathrm{L}, P=0.018$, Table 3). Equally, in each group of female CNSI, 
Table 4: Serum UA, Tbil, Ibil, and albumin levels of patients with each group of CNSI (mean \pm SD)

\begin{tabular}{|c|c|c|c|c|c|c|}
\hline Patients & Total & Male & Female & $P^{1 \dagger}$ & $P^{2 \dagger}$ & $P^{3 \dagger}$ \\
\hline \multicolumn{7}{|l|}{ Serum UA levels $(\mu \mathrm{mol} / \mathrm{L})$} \\
\hline $\begin{array}{l}\text { Viral meningitis and/or } \\
\text { meningoencephalitis }\end{array}$ & $261.94 \pm 107.88$ & $285.89 \pm 101.81$ & $230.17 \pm 108.56$ & $<0.001$ & $<0.001$ & 0.227 \\
\hline Cysticercosis of brain & $275.20 \pm 92.02$ & $319.87 \pm 77.33$ & $213.44 \pm 73.63$ & 0.001 & 0.005 & 0.066 \\
\hline $\begin{array}{l}\text { Tuberculous meningitis and/or } \\
\text { meningoencephalitis }\end{array}$ & $286.77 \pm 197.39$ & $339.49 \pm 220.30$ & $215.23 \pm 133.18$ & 0.003 & 0.022 & 0.080 \\
\hline $\begin{array}{l}\text { Cryptococcus meningitis and/or } \\
\text { meningoencephalitis }\end{array}$ & $224.46 \pm 123.41$ & $233.96 \pm 127.26$ & $201.82 \pm 112.82$ & $<0.001$ & $<0.001$ & 0.042 \\
\hline $\begin{array}{l}\text { Bacterial meningitis and/or } \\
\text { meningoencephalitis }\end{array}$ & $197.27 \pm 93.73$ & $100.95 \pm 96.98$ & $186.22 \pm 86.21$ & $<0.001$ & $<0.001$ & 0.034 \\
\hline \multicolumn{7}{|l|}{ Serum Tbil levels ( $\mu \mathrm{mol} / \mathrm{L})$} \\
\hline $\begin{array}{l}\text { Viral meningitis and/or } \\
\text { meningoencephalitis }\end{array}$ & $15.75 \pm 9.93$ & $18.41 \pm 11.78$ & $12.29 \pm 5.18$ & 0.682 & 0.336 & 0.018 \\
\hline Cysticercosis of brain & $10.91 \pm 4.78$ & $11.54 \pm 4.89$ & $10.01 \pm 4.55$ & $<0.001$ & 0.003 & $<0.001$ \\
\hline $\begin{array}{l}\text { Tuberculous meningitis and/or } \\
\text { meningoencephalitis }\end{array}$ & $14.41 \pm 11.15$ & $15.19 \pm 13.13$ & $13.35 \pm 7.73$ & 0.111 & 0.350 & 0.111 \\
\hline $\begin{array}{l}\text { Cryptococcus meningitis and/or } \\
\text { meningoencephalitis }\end{array}$ & $13.29 \pm 9.22$ & $14.51 \pm 9.78$ & $10.45 \pm 7.10$ & 0.011 & 0.164 & 0.001 \\
\hline $\begin{array}{l}\text { Bacterial meningitis and/or } \\
\text { meningoencephalitis }\end{array}$ & $13.16 \pm 7.74$ & $13.87 \pm 8.50$ & $11.27 \pm 4.96$ & 0.025 & 0.121 & 0.025 \\
\hline \multicolumn{7}{|l|}{ Serum Ibil levels ( $\mu \mathrm{mol} / \mathrm{L})$} \\
\hline $\begin{array}{l}\text { Viral meningitis and/or } \\
\text { meningoencephalitis }\end{array}$ & $11.90 \pm 7.43$ & $14.06 \pm 8.87$ & $9.11 \pm 3.68$ & 0.181 & 0.550 & 0.001 \\
\hline Cysticercosis of brain & $9.04 \pm 3.93$ & $9.40 \pm 3.86$ & $8.52 \pm 4.02$ & $<0.001$ & 0.001 & $<0.001$ \\
\hline $\begin{array}{l}\text { Tuberculous meningitis and/or } \\
\text { meningoencephalitis }\end{array}$ & $9.93 \pm 7.48$ & $10.28 \pm 8.78$ & $9.47 \pm 5.29$ & $<0.001$ & 0.011 & 0.002 \\
\hline $\begin{array}{l}\text { Cryptococcus meningitis and/or } \\
\text { meningoencephalitis }\end{array}$ & $9.49 \pm 5.82$ & $10.21 \pm 6.02$ & $7.81 \pm 5.03$ & $<0.001$ & 0.007 & $<0.001$ \\
\hline $\begin{array}{l}\text { Bacterial meningitis and/or } \\
\text { meningoencephalitis }\end{array}$ & $10.11 \pm 5.68$ & $10.46 \pm 6.00$ & $9.17 \pm 4.79$ & 0.003 & 0.028 & 0.017 \\
\hline \multicolumn{7}{|l|}{ Serum albumin levels ( $g / L$ ) } \\
\hline $\begin{array}{l}\text { Viral meningitis and/or } \\
\text { meningoencephalitis }\end{array}$ & $42.65 \pm 5.03$ & $42.73 \pm 5.69$ & $42.54 \pm 4.05$ & $<0.001$ & $<0.001$ & $<0.001$ \\
\hline Cysticercosis of brain & $42.82 \pm 3.08$ & $43.18 \pm 3.05$ & $42.29 \pm 3.10$ & $<0.001$ & $<0.001$ & $<0.001$ \\
\hline $\begin{array}{l}\text { Tuberculous meningitis and/or } \\
\text { meningoencephalitis }\end{array}$ & $41.40 \pm 5.24$ & $42.34 \pm 4.81$ & $40.13 \pm 5.58$ & $<0.001$ & $<0.001$ & $<0.001$ \\
\hline $\begin{array}{l}\text { Cryptococcus meningitis and/or } \\
\text { meningoencephalitis }\end{array}$ & $41.47 \pm 5.27$ & $42.52 \pm 4.95$ & $39.02 \pm 5.27$ & $<0.001$ & $<0.001$ & $<0.001$ \\
\hline $\begin{array}{l}\text { Bacterial meningitis and/or } \\
\text { meningoencephalitis }\end{array}$ & $39.90 \pm 6.87$ & $39.11 \pm 7.16$ & $41.99 \pm 5.71$ & $<0.001$ & $<0.001$ & $<0.001$ \\
\hline
\end{tabular}

we found serum UA levels were lower than those of female $\mathrm{HC}$, as shown in Table 4.

For serum Tbil and indirect bilirubin (Ibil), we found that serum total levels in CNSI were significantly lower than $\mathrm{HC}(13.67 \pm 9.2 \mu \mathrm{mol} / \mathrm{L}, P=0.015$ and $10.18 \pm$ $6.43 \mu \mathrm{mol} / \mathrm{L}, P<0.001)$ respectively. In each group of $\mathrm{CNSI}$, serum Tbil levels of patients with $\mathrm{BC}, \mathrm{CM}$, and BM were significantly lower when compared with $\mathrm{HC}$. For serum Ibil levels, patients with CNSI were also lower, except for VM [Table 4]. Besides, we further divided each group into male and female subgroups. In both subgroups, compared to $\mathrm{HC}$, we found that serum Tbil and Ibil levels in CNSI were significantly lower, except for male serum Tbil $(P=0.099$, Table 3$)$.

For albumin, we found that total serum levels in CNSI were lower than $\mathrm{HC}(41.80 \pm 5.16$ and $47.10 \pm 2.83$, $P=0.000$, Table 3 ). We came to a similar conclusion in each group of CNSI. Interestingly, similar results have been observed in male and female subgroups as well [Table 4].

\section{DISCUSSION}

Our study showed that there were reducing serum levels of UA, bilirubin and albumin in CNSI patients. Interestingly, these results were also observed when we divided cohorts into male and female groups. Our studies have shown that patients with CNSI have lower serum UA, which were consistent with previous reports. ${ }^{[17]}$ Similar results that CNSI patients with lower serum albumin and bilirubin levels than $\mathrm{HC}$ groups were also observed. Similar relevant results were not 
reported before. In conclusion, our findings suggest that there were low serum levels of UA, bilirubin and albumin in patients with $\mathrm{CNSI}$.

The mechanisms of CNS damage during meningitis have not been conclusively identified. Increasing evidence shows a massive production of ROS and RNS could lead to significant collateral damage in pneumococcal meningitis, because of their toxic actions, such as lipid peroxidation, DNA strand breakage and production of inflammatory cytokines. Therefore, a potential use of oxidative inhibitors as an adjunctive treatment could be beneficial in treating meningitis. ${ }^{[18]}$ Our work showed that patients with CNSI had low serum UA, Tbil, Ibil and albumin levels. The notion is that oxidative damage plays a crucial role in CNSI, which may be because of the low antioxidant status.

UA is a natural antioxidant in the blood and brain, which has been shown that exogenous administration of urate is protective in experimental bacterial meningitis. ${ }^{[19]}$ UA is capable of scavenging free radicals and chelating transitional metal ions by preventing peroxynitrite induced protein nitrosylation, lipid and protein peroxidation, and inactivation of tetrahydrobiopterin. ${ }^{[20]}$ Low levels of UA are detrimental to neurons, while high levels of UA contribute to neuroprotection. ${ }^{[21,22]}$

Our study showed that serum levels of UA in patients with CNSI were lower, therefore, increasing in UA concentration has been suggested as one of the possible mechanisms as a replacement therapy. Generally speaking, serum UA levels are highly sex and age dependent. In this study, we further divided each group into female and male subgroups, ${ }^{[23]}$ we found that in all groups, men had higher serum UA levels than women which is consistent with previous

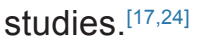

Bilirubin, the end product of heme metabolism, is formed from biliverdin. As the products of Hemeoxygenase (HO)-catalyzed heme breakdown, it has an essential cerebroprotective role. ${ }^{[11,12]}$ There are two major forms of $\mathrm{HO}$, existing $\mathrm{HO}-1$ and $\mathrm{HO}-2$. It is generally accepted that the elevated HO-1 levels represent an attempt to restore redox homeostasis and to down-modulate inflammation. ${ }^{[25]} \mathrm{HO}-2$, the constitutively active isoform, has an essential cerebroprotective role against seizure-induced loss of endothelial vasodilator function in newborn piglets. ${ }^{[26]}$ Some observations suggested that bilirubin, as a potent antioxidant, could reduce cerebrovascular complications in the seizures of newborn babies. ${ }^{[12]}$ Some scholars provided that bilirubin could be as neuroprotectant against oxidative stress injury. ${ }^{[27]}$ Moreover, increasing evidences suggested that bilirubin also possessed multiple biological activities, including potential immunomodulatory properties. ${ }^{[28]}$ Our results supported the finding that serum bilirubin levels in CNSI were lower than the control group, in spite of there being no apparent difference when compared with multiple sclerosis (MS). Furthermore, gender differences also existed, and we found that women also had lower mean serum bilirubin values when compared with men.

Otherwise, some researchers demonstrated that serum albumin, specifically block echovirus by inhibiting the uncoating step in the virus replication cycle. That is to say that in man, echovirus infection may be modulated by serum albumin. ${ }^{[29]}$

Imbalanced metabolism and excess free radical generation could cause oxidative stress, which has been defined as a principle pathological cause of neurodegenerative disorders, such as $M S,{ }^{[23]}$ Parkinson's disease. ${ }^{[30]}$ Therefore, it could be favorable for increasing antioxidant levels, such as UA, bilirubin and albumin levels in CNSI, which should not focus only on anti-infective therapy, but also on the antioxidant effects.

In conclusion, low serum UA, bilirubin and albumin levels in CNSI patients were found in our study, the reason may be due to exhaustion of antioxidant capacity. An imbalance between oxidant and antioxidant activities will result in the development of intracranial inflammation and destruction of neurons. These findings may increase our understanding of pathophysiology of CNSI. Therefore, to enhance antioxidant power and keep oxidative stress and antioxidant in balance may be beneficial to patients with CNSI, that is to say, improving the clinical and laboratory results in CNSI, by elevating serum UA, bilirubin and albumin could be considered.

In the future, we plan to measure the antioxidant levels in cerebrospinal fluid (CSF) of CNSI patients, and we may compare the antioxidant status of blood and CSF in these patients.

\section{Financial support and sponsorship} Nil.

\section{Conflicts of interest \\ There are no conflicts of interest.}

\section{Patient consent}

Informed consent was obtained from all individual participants included in the study. 


\section{Ethics approval}

Data collection in our study involving the patient is consistent with the ethical standards of the institution's ethics committee.

\section{REFERENCES}

1. Nadal D. Progress in the understanding of the pathogenesis and prevention of bacterial otitis media and meningitis. Schweiz Med Wochenschr 1999;129:2017-20. (in German)

2. Leib SL, Tauber MG. Pathogenesis of bacterial meningitis. Infect Dis Clin North Am 1999;13:527-48, v-vi.

3. Cheeseman KH, Slater TF. An introduction to free radical biochemistry. Br Med Bull 1993;49:481-93.

4. Koedel U, Pfister HW. Oxidative stress in bacterial meningitis. Brain Pathol 1999;9:57-67.

5. Kurien BT, Scofield RH. Autoimmunity and oxidatively modified autoantigens. Autoimmun Rev 2008;7:567-73.

6. Hamed SA, Hamed EA, Zakary MM. Oxidative stress and S-100B protein in children with bacterial meningitis. BMC Neurol 2009;9:51.

7. Gutteridge JM, Halliwell B. Free radicals and antioxidants in the year 2000. A historical look to the future. Ann N Y Acad Sci 2000;899:136-47.

8. Koprowski H, Spitsin SV, Hooper DC. Prospects for the treatment of multiple sclerosis by raising serum levels of uric acid, a scavenger of peroxynitrite. Ann Neurol 2001;49:139.

9. Toncev G, Milicic B, Toncev S, Samardzic G. Serum uric acid levels in multiple sclerosis patients correlate with activity of disease and blood-brain barrier dysfunction. Eur J Neurol 2002;9:221-6.

10. Becker BF, Kastenbauer S, Kodel U, Kiesl D, Pfister HW. Urate oxidation in CSF and blood of patients with inflammatory disorders of the nervous system. Nucleosides Nucleotides Nucleic Acids 2004;23:1201-4.

11. Stocker R. Antioxidant activities of bile pigments. Antioxid Redox Signal 2004;6:841-9.

12. Parfenova H, Leffler CW, Basuroy S, Liu J, Fedinec AL. Antioxidant roles of heme oxygenase, carbon monoxide, and bilirubin in cerebral circulation during seizures. J Cereb Blood Flow Metab 2012;32:1024-34

13. Bernardi M, Ricci CS, Zaccherini G. Role of human albumin in the management of complications of liver cirrhosis. J Clin Exp Hepatol 2014;4:302-11.

14. Erel O. A novel automated method to measure total antioxidant response against potent free radical reactions. Clin Biochem 2004;37:112-9.
15. Bahr NC, Boulware DR. Methods of rapid diagnosis for the etiology of meningitis in adults. Biomark Med 2014;8:1085-103.

16. Garcia HH, Nash TE, Del Brutto OH. Clinical symptoms, diagnosis, and treatment of neurocysticercosis. Lancet Neurol 2014;13:1202-15.

17. Liu J, Li M, Wang X, Yi H, Xu L, Zhong XF, Peng FH. Serum uric acid levels in patients with infections of central nervous system. Acta Neurol Belg 2016;116:303-8.

18. Klein M, Koedel U, Pfister HW. Oxidative stress in pneumococcal meningitis: a future target for adjunctive therapy? Prog Neurobiol 2006;80:269-80

19. Kastenbauer S KU, Pfister HW. Role of peroxynitrite as a mediator of pathophysiological alterations in experimental pneumococcal meningitis. J Infect Dis 1999;180:1164-70.

20. Kang DH, Ha SK. Uric acid puzzle: dual role as anti-oxidantand prooxidant. Electrolyte Blood Press 2014;12:1-6.

21. Fang P, Li X, Luo JJ, Wang H, Yang XF. A double-edged sword: uric acid and neurological disorders. Brain Disord Ther 2013;2:109.

22. Yan S, Zhang P, Xu W, Liu Y, Wang B, Jiang T, Hua C, Wang X, $\mathrm{Xu}$ D, Sun B. Serum uric acid increases risk of cancer incidence and mortality: a systematic review and meta-analysis. Mediators Inflamm 2015;2015:764250.

23. Jesus S, Perez I, Caceres-Redondo MT, Carrillo F, Carballo M, Gomez-Garre P, Mir P. Low serum uric acid concentration in Parkinson's disease in southern Spain. Eur J Neurol 2013;20:208-10.

24. Drulovic J, Dujmovic I, Stojsavljevic N, Mesaros S, Andjelkovic S, Miljkovic D, Peric V, Dragutinovic G, Marinkovic J, Levic Z, Mostarica Stojkovic M. Uric acid levels in sera from patients with multiple sclerosis. J Neurol 2001;248:121-6.

25. Cuadrado A, Rojo AI. Heme oxygenase-1 as a therapeutic target in neurodegenerative diseases and brain infections. Curr Pharm Des 2008; 14:429-42

26. Parfenova H, Leffler CW. Cerebroprotective functions of HO-2. Curr Pharm Des 2008;14:443-53.

27. Dore S, Takahashi M, Ferris CD, Zakhary R, Hester LD, Guastella D, Snyder SH. Bilirubin, formed by activation of heme oxygenase-2, protects neurons against oxidative stress injury. Proc Natl Acad Sci U S A 1999;96:2445-50.

28. Munoz-Sanchez J, Chanez-Cardenas ME. A review on hemeoxygenase-2: focus on cellular protection and oxygen response. Oxid Med Cell Longev 2014;2014:604981.

29. Ward T, Powell RM, Evans DJ, Almond JW. Serum albumin inhibits echovirus 7 uncoating. J Gen Virol 1999;80:283-90.

30. Guerrero AL, Martin-Polo J, Laherran E, Gutierrez F, Iglesias F, Tejero MA, Rodriguez-Gallego M, Alcazar C. Variation of serum uric acid levels in multiple sclerosis during relapses and immunomodulatory treatment. Eur J Neurol 2008;15:394-7. 